\title{
PERUBAHAN STRUKTUR DAN ARRANSEMEN MUSIK GAMAD DI KOTA PADANG
}

\author{
Ioqo Alhamra Fikri ${ }^{*}$, Ardipal ${ }^{2 *}$ \\ Program Studi Pendidikan Ilmu Pengetahuan Sosial Konsentrasi Pendidikan Seni dan Budaya \\ Program Pascasarjana \\ Universitas Negeri Padang \\ Jl. Prof. Dr. Hamta, Air Tawar Padang, Kel. Air Tawar Barat, Kec. Padang Utara, Kota Padang, Kode Pos 25171 \\ Sumatera Barat. Indonesia \\ Email: ioqoaf@gmail.com
}

\begin{abstract}
Abstrak
Musik Gamad merupakan sebuah kesenian khas dari kota Padang yang mana pada dasarnya secara musikologi kesenian ini masih tergolong dalam klasifikasi musik melayu namun memiliki keunikan tersendiri dikarenakan pantun-pantun yang menjadi syair lagu dinyanyikan dalam bahasa Minangkabau dan juga bersifat spontan.kesenian ini juga merupakan sebuah bentuk akulturasi dari beberapa budaya masyarakat yang ada di kota padang pada era perkembanganya hingga pada saat ini.dilatar belakangi oleh kedatangan bangsa portugis dengan budaya musik barat dengan cepat menjadi daya tarik bagi bumi putra dalam konsep bermain musik sehingga pada sebelumnya pantun hanya dinyanyikan oleh vokal dengan iringan gendang tradisional kemudian bertambah dengan alat musik seperti akordeon,biola dan gitar.musik gamad pun dengan cepat menjadi sebuah kesenain yang populer di kota padang,namun dengan seiring perkembangan zaman dan pergeseran nilai-nilai sosial yang terjadi dalam masyarakat kota padang turut mempengaruhi kesenian ini sehingga terjadilah perubahan struktur dan bentuk dalam arransemen musik gamad di kota Padang.
\end{abstract}

Kata Kunci: gamad, struktur, bentuk, arransemen.

\begin{abstract}
Gamad music is a distinctive art from the city of Padang, which is basically a musical artistry is still classified in the Malay music classification but has its own uniqueness because the poems are poetry sung in the Minangkabau language and are also spontaneous. This art is also a form acculturation of several cultural communities in the city of Padang in the era of its development until today. The background of the arrival of the Portuguese with Western music culture quickly became an attraction for the son of the earth in the concept of playing music so that in the past pantun was only sung by vocals with accompaniment traditional drum and then increased with musical instruments such as accordions, violins and guitars. Gamad music also quickly became a popular game in the city of Padang, but with the development of the times and the shifting of social values that occur in the city of Padang society also influence to this art so that there was a change in structure and shape in the gamad music arrangement in the city of Padang.
\end{abstract}

Keywords: gamad, structure, shape, arrangement.

\section{PENDAHULUAN}

Manusia memiliki beragam budaya, yang secara totalitas menghasilkan suatu kebudayaan untuk saling berinteraksi antara satu dengan yang lainnya. (Koentjaraninggrat 1996) menyatakan bahwa kebudayaan adalah "keseluruhan sistem gagasan tindakan, dan hasil karya manusia dalam rangka kehidupan masyarakat yang dijadikan milik manusia dengan belajar.Pernyataan ini menggambarkan bahwa kesenian tradisional merupakan hasil gagasan kolektif maupun gagasan perorangan yang dimiliki oleh masyarakat pendukungnya.

Dimana setiap anggota masyarakat berkewajiban untuk mengembangkan dan mempertahankan kesenian dan budaya yang ada, agar tidak terpinggirkan seiring berjalannya waktu dan perkembangan zaman. Provinsi Sumatera Barat memiliki kesenian tradisional yang beraneka ragam. Ciri khas kesenian ini dipengaruhi oleh kepribadian, kebiasaan , adat istiadat, pengetahuan masyarakat, tempat tumbuh berkembangnya kesenian itu sendiri. Salah satu diantara kesenian tradisional kota Padang yang terkenal adalah Gamad.

Rizaldi (1994) mengatakan bahwa, kata gamad menurut etimologi bahasa berasal dari kata gamit yang artinya menyentuh seseorang dengan jari yang bertujuan untuk mengajak orang bercakap-cakap atau untuk keperluan lainnya. Menurut (Rizaldi 1994), musik gamad lahir dari pencampurbauran antara 
budaya bumi putra dengan budaya barat alkulturasi yang hidup dan berkembang dalam masyarakat Minangkabau, khususnya dikota Padang. Sejalan dengan itu, (Koentjaraningrat 1996) melihat akulturasi sebagai proses sosial yang terjadi apabila kelompok sosial dengan kebudayaan tertentu dihadapkan pada kebudayaan asing. Syarat terjadinya proses akulturasi adalah adanya persenyawaan affinity yaitu penerimaan kebudayaan tanpa adanya kekhawatiran akan hilangnya kebudayaan bumi putra dan syarat lainnya adalah adanya keserupaan homogeneity seperti nilai baru yang tercerna akibat keserupaan tingkat dan corak budaya. Disisi lain akulturasi juga menngambarkan perpaduan antara dua budaya yang menghasilkan budaya baru tanpa menghilangkan unsur-unsur asli dari budaya tersebut. Misalnya, proses pencampuran dua budaya atau lebih yang saling bertemu dan saling mempengaruhi.musik gamad lahir dari akulturasi budaya bumi putra dan budaya barat dalam hal ini Portugis.

Namun bagi masyarakat kota Padang musik gamad sudah dianggap sebagai milik dan bahagian dari tradisi masyarakat, yang dibuktikan dengan tetap dijaga dan dilestarikannya oleh masyarakat Kota Padang. Musik gamad tidak terlepas dari sejarah panjang yang melatar belakangi kehadirannya, yaitu sejarah tentang kedatangan bangsa Portugis di pantai barat pulau Sumatera pada abad ke 16. (Indrayuda 2008) menjelaskan bahwa abad sebelum tanggal 7 Agustus tahun 1969, Padang hanya merupakan perkampungan tradisional yang terletak di pinggiran pantai Sumatera bagian barat, namun tempat ini mulai ramai semenjak orang portugis dan aceh datang untuk berdagang ke kota Padang pada masa itu. Dengan adanya kehadiran bangsa Portugis di kota Padang sebagai pedagang, maka berdatangan pulalah penduduk imingran dari pulau Nias untuk bekerja sebagai buruh atau pembantu dipelabuhan bagi bangsa Portugis.

Kedatangan orang Nias dibawa oleh para pedagang China yang datang ke Sumatera Barat pada awal abab ke-16. Pertunjukan musik gamad, biasanya diikuti oleh tari-tarian spontan yang terdiri dari dua sampai empat orang, dimana mereka menari dengan mengunakan gerakan bebas dihadapan penyanyi dan menggunakan selendang atau sapu tangan sebagai media menari. Penggunaan selendang atau sapu tangan tersebut dapat dilihat ketika sipenari memberikan selendang atau sapu tangan tersebut kepada salah satu penonton, yang menandakan bahwa orang tersebut diminta dengan hormat untuk berpartisipasi dan ikut menari pada lagu berikutnya. Cara memberikan selendang atau sapu tangan tersebut dikenal dengan istilah menggamit, sehingga musik ini dinamakan musik gamad.

\section{KAJIAN TEORI \\ 1.Gamad}

Musik gamad terdiri dari gabungan vokal dan instrumental, yang secara umum menggunakan biola, akordeon, gitar, gendang, dan bass sebagai instrumennya.Vokal berperan sebagai pembawa lagu yang liriknya berupa pantun-pantun Minangkabau yang bersifat metafora (kiasan). Pada umumnya orang Padang, baik yang tinggal di perkampungan maupun yang berada di rantau (di luar Provinsi Sumatera Barat) mengetahui dengan jelas kata ini apabila ditanya dan setidak-tidaknya mereka mengetahui salah satu judul lagu yang biasa dinyanyikan oleh musik ini, misalnya lagu duo. Bagi mereka yang mempunyai perhatian lebih dalam terhadap musik, dapat menunjukkan ciri khas dari musik ini misalnya penggunaan akordeon, biola, dan gendang dalam pertunjukannya. Dalam gamad terdapat dua jenis tempo musik yaitu :

1).Gembira / joget

Lagu gembira / joget, biasanya dibawakan dengan menggunakan tempo yang cepat, dimana lagu ini akan mengajak para penonton untuk berjoget secara spontan. 2).Sedih / langgam

Lagu Sedih/langgam biasanya dibawakan dengan menggunakan tempo lambat.

Dalam musik gamad terdapat pintu-pintu lagu (fill in) yang bertujuan memudahkan para penyanyi untuk bernyanyi,begitu juga dengan instrument yang digunakan. Pada awalnya, musik gamad hanya terdiri dari biola, akordeon, gitar dan gendang.seiring dengan perkembangan waktu, musik gamad juga dapat dimainkan dengan menggunakan instrument musik barat lainnya. Tangga nada yang digunakan dalam musik gamad, merupakan tangga nada yang berasal dari musik barat yaitu tangga nada diatonis. Musik gamad memiliki ciri tersendiri yaitu dengan adanya cengkok dan garinyiak yang dapat menciptakan lantunan nada yang mendayu-dayu. Ciri khas tersebut tercipta melalui improvisasi melodi yang dilakukan baik pada vokal maupun instrument melodi yang digunakan.

\section{Bentuk}

Bentuk adalah wujud, rupa yang ditangkap oleh indera manusia. Bentuk seni sebagai penciptaan seniman merupakan wujud dan ungkapan isi, pandangan dan tanggapannya ke dalam bentuk fisik yang dapat ditangkap oleh panca indera.Menurut (Bastomi 1982) bentuk adalah wujud atau fisik yang dapat dilihat. Bentuk hasil seni ada yang visual yaitu hasil seni yang 


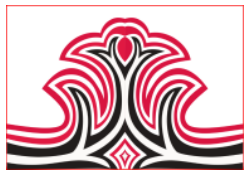

dapat dihayati dengan indera pandang yaitu seni rupa, ada juga yang disampaikan melalui serangkaian gerak ritmis yang harmonis.

\section{Struktur}

Adalah sebuah

sifat fundamental

bagi

setiap sistem yang dalam penggunaannya sering dapat di petukarkan dengan kata-kata. Identifikasi suatu struktur adalah suatu tugas subjektif, karena tergantung pada asumsi kriteria bagi pengenalan bagianbagiannya, dan hubungan mereka. Karenanya, identifikasi kognitif suatu struktur berorientasi tujuan dan tergantung pada pengetahuan yang ada. struktur juga diartikan suatu tatanan yang membentuk suatu kelompok dalam masyarakat. Struktur memiliki 3 ciri yakni dapat berubah dan berkembang, ada di dalam masyarakat, dan berhubungan erat dengan masyarakat. Dalam musik struktur merupakan sebuah tatanan konstruksi dari elemen-elkomponen-komponen musikal yang menjadi sebuah rangkaian dalam sebuah komposisi musik.

\section{Aransemen}

Aransemen Musik Menurut (Banoe2003) aransemen atau arrangement merupakan gubahan lagu untuk permainan bersama baik vokal maupun instrumental. Orang yang membuat aransemen lagu disebut arranger. Modal dasar yang harus dimiliki arranger adalah penguasaan pengetahuan tentang harmoni.

\section{METODE PENELITIAN}

Jenis penelitian yang digunakan dalam penelitian ini adalah jenis penelitian kualitatif dengan pendekatan musikologis.

Jenis penelitian kualitatif adalah prosedur penelitian yang menghasilkan data deskriptif berupa kata-kata tertulis atau lisan dari orang-orang dan perilaku yang dapat diamati. Dalam penelitian kualitatif, data yang diperoleh tidak dapat dituangkan dalam bentuk bilangan atau angka statistik, peneliti memaparkan gambaran mengenai hasil yang diteliti dalam bentuk naratif untuk mendeskripsikan atau menggambarkan fenomena-fenomena yang ada di objek penelitian. Dalam hal ini, yang menjadi objek penelitian adalah seorang arranger musik gamad dan sekaligus pemilik studio rekman "Badul Studio" di padang.

Peneliti memfokuskan penelitian ini pada aransemen musik gamad. Kriteria derajat kepercayaan menuntut suatu penelitian kualitatif agar dapat dipercaya oleh pembaca yang kritis dan dapat dibuktikan oleh orangorang yang menyediakan informasi yang dikumpulkan selama penelitian berlangsung. (Moleong1989)
Gorga Jurnal Seni Rupa

Volume 08 Nomor 02 Juli-Desember 2019 p-ISSN: 2301-5942 | e-ISSN: 2580-2380

triangulasi dengan sumber berarti membandingkan dan mengecek baik derajat kepercayaan suatu informasi yang diperoleh melalui waktu dan alat yang berbeda dalam metode kualitatif.

\section{HASIL DAN PEMBAHASAN \\ 1.Hasil}

Pada penelitian ini penulis menjadikan lagu kaparinyo pulau batu yang telah digubah oleh seorang musikus gamad di kota padang sebagai objek perbandingan terkait dengan perubahan struktur dan arransemen dalam musik gamad di kota padang.adapun beberapa komponen musikal yang mengalami perubahan dari lagu kaparinyo pulau batu akan dijelaskan sebagai berikut:

\section{1).Melodi Intro}

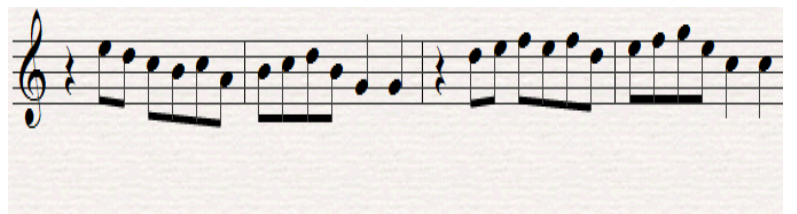

Gambar 1. Melody Intro pada Lagu Asli "Kaparinyo Pulau Batu".. (Sumber: Ioqo Alhamra Fikri, 2019)

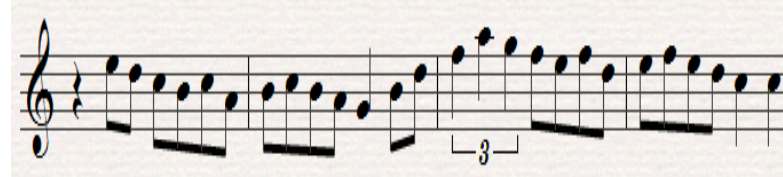

Gambar 2. Melody Intro pada Lagu "Kaparinyo Pulau Batu" Sesudah Diarransemen. (Sumber: Ioqo Alhamra Fikri, 2019)

\section{2).Pintu Lagu}

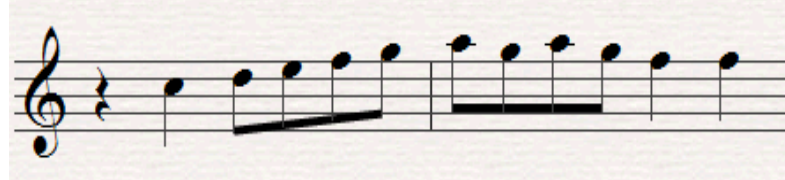

Gambar 3. Pintu Lagu pada Lagu Asli "Kaparinyo Pulau Batu". (Sumber: Ioqo Alhamra Fikri, 2019)

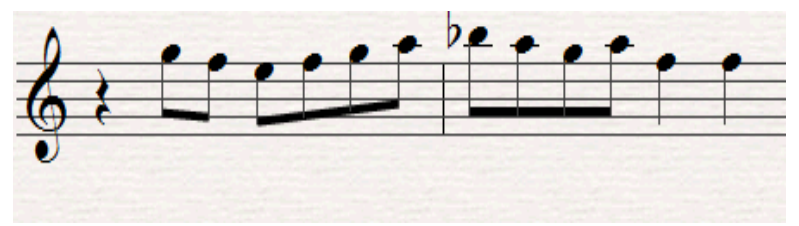

Gambar 4. Pintu Lagu pada Lagu Asli "Kaparinyo Pulau Batu" Sesudah Diarransemen. (Sumber: Ioqo Alhamra Fikri, 2019) 


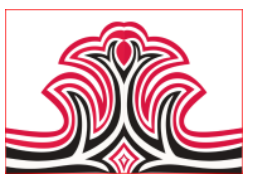

3).Melodi Interlude

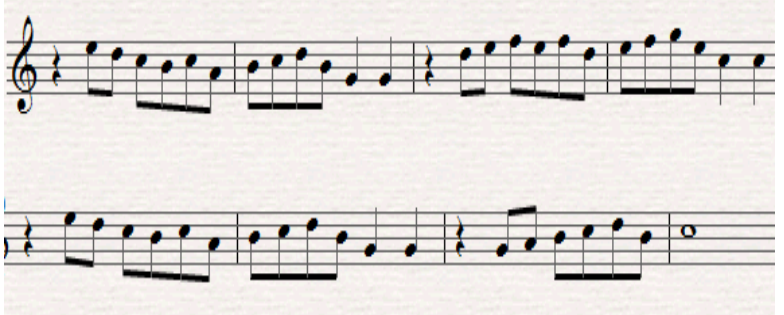

Gambar 5. Interlude Lagu pada Lagu Asli "Kaparinyo Pulau Batu". (Sumber: Ioqo Alhamra Fikri, 2019)

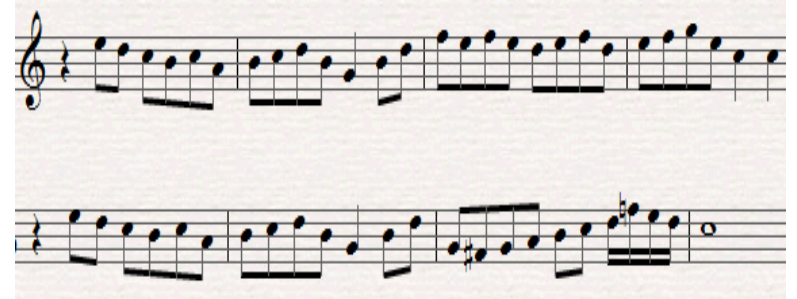

Gambar 6. Interlude Lagu pada Lagu "Kaparinyo Pulau Batu" Sesudah Diarransemen

(Sumber: Ioqo Alhamra Fikri, 2019)

\section{4).Lirik Lagu}

Dalam pengamatan peneliti terhadap objek penelitian bahwasanya tidak ditemukan perbedaan Pada lirik lagu kaparinyo pulau batu,adapun isi dari pantun lagunya sebagai berikut:

Bulan dimanao ka bacahayo

Bulan dimanao ka bacahayo

Bilo ditutuik dek awan hitam

Bilo ditutuik dek awan hitam

Antah dimano salah dikiro

Antah dimano salah dikiro

Mangkonyo urang bahati dandam

Mangkonyo urang bahati dandam

Tanyo ka bintang di langik tinggi

Tanyo ka bintang di langik tinggi

Manga kok anggan nan mangawani

Manga kok anggan nan mangawani

Tagak dimano si badan diri

Tagak dimano si badan diri

Ndak suran gjuo nan acuah lai

Ndak suran gjuo nan acuah lai

Mungkin hujan di tangah malam

Mungkin hujan di tangah malam

Guruah jo patuih solang manyolang

Guruah jo patuih solang manyolang

Ambo ko pai bukanyo dandam

Ambo ko pai bukanyo dandam

Pado di kampuang di hino urang

Pado di kampuang di hino urang.
Gorga Jurnal Seni Rupa

Volume 08 Nomor 02 Juli-Desember 2019 p-ISSN: 2301-5942 | e-ISSN: 2580-2380

\section{Pembahasan}

\section{Skema Lagu Kaparinyo Pulau Batu}

\section{1).Bagian Intro}

Dalam bagian ini perbedaan antara lagu kaparinyo pulau batu sebelum ataupun sesudah diarransemen,hanyan terletak pada penggunaan alat yang memainkan melodi utama dan melodi yang sudah dipaparkan pada bagian isi. Dalam bagian ini perbedaan antara lagu kaparinyo pulau batu sebelum ataupun sesudah diarransemen, hanyan terletak pada penggunaan alat yang memainkan melodi utama dan melodi yang sudah dipaparkan pada bagian isi. Gitar,keyboard,bass dan gandang menjadi instrument pengiring melodi baik dari segi harmoni dan juga pembawa ritem jogged, progressi akor yang digunakan adalah: A.../E.../E../A.../A.../E.../E.../A.../A.../2

\section{2).Lagu Bagian Pertama}

kalimat anteseden, melodi dimainkan dalam tangga nada A mayor, cadence yang di pakai adalah perfect authentic cadence V-I dan Akordeon mengisi filler melody.

Lirik lagu pada bagian pertama :

Bulan dimanao ka bacahayo

Bulan dimanao ka bacahayo

Bilo ditutuik dek awan hitam

Bilo ditutuik dek awan hitam

Antah dimano salah dikiro

Antah dimano salah dikiro

Mangkonyo urang bahati dandam

Mangkonyo urang bahati dandam

Tanyo ka bintang di langik tinggi

Tanyo ka bintang di langik tinggi

Manga kok anggan nan mangawani

Manga kok anggan nan mangawani

Tagak dimano si badan diri

Tagak dimano si badan diri

Ndak suran gjuo nan acuah lai

Ndak suran gjuo nan acuah lai

\section{3).Interlude}

Intrerlude mainkan oleh akordeon dan biola, Progresi akor yang digunakan adalah:E.../A.../E.../A.../A.../D .../D .../A.../D .../D .../A.../A.../E.../E.../A.../A.../E.../E.../A.../A...

4). Lagu bagian ke dua

kalimat anteseden, dimainkan dalam tangga nada A mayor dan cadence yang di pakai adalah perfect authentic cadence V-I.Lirik lagu pada bgain ke dua:

Mungkin hujan di tangah malam

Mungkin hujan di tangah malam

Guruah jo patuih solang manyolang

Guruah jo patuih solang manyolang 
Ambo ko pai bukanyo dandam

Ambo ko pai bukanyo dandam

Pado di kampuang di hino urang

Pado di kampuang di hino urang

\section{5).Coda}

Akordeon memainkan melodi pentup dalam tangga nada A mayor, Melodi pada bagian coda kembali memainkan melodi intro, Keboard,bass,gitar dan gandang berfungsi sebagai ritem dan harmoni. Progresi akor yang digunakan adalah:

E.../E.../A.../A.../E.../E.../A.../A...dan cadence yang di pakai adalah perfect authentic cadence V-I.

\section{KESIMPULA DAN SARAN}

\section{Kesimpulan}

Musik gamad tidak hanya berperan sebagai sebuah kesenian rakyat yang berkembang di kota padang,akan tetapi lebih dari itu kesenian ini bisa dijadikan referensi budaya dalam perkembangan srtuktur sosial masyrakat di kota padang.Perubahan struktur dan bentuk arransemen musik gamad merupakan salah satu upaya dalam melestarikan kesenian tersebut dalam menghadapi era globalisasi yang cenderung didominasi oleh kesenian musik populer,jika tidak demikian lambat laun kesenian khas dari kota padang ini kan ditinggalkan oleh masyarakatnya,terutama generasi muda apabila tidak ada bentuk pembaharauan yang menyesuaikan dengan pola kebutuhan masyarakat pada saat ini.

\section{Saran}

Sebagai langkah untuk melestarikan dan menjaga eksistensi dari kesenian ini,diperlukanya kajian ilmiah dalam bentuk seminar ataupun workshop dan juga pertunjukan yang dapat meningkatkan kesadaran kolektif masyarakat terhadap pentingnya menjaga eksistensi dari sebuah kesenian masyarakat agar tidak hilang.

\section{DAFTAR RUJUKAN}

Bastomi, Suwaji. (1992). Seni pertunjukan. Semarang: IKIP Semarang Press.

Banoe, Pono. (2003). Kamus Musik. Yogyakarta:

Kanisius.

Indrayudha. (2008). Tari Balance Madam Pada

Masyarakat Nias Padang Sebuah Perspektif

Etnologi. Padang:

Koentjaraningrat. (1996). Pengantar Antropologi

Budaya I. Jakarta: Rineka Cipta.

Moleong, Lexy. J. (1989). Metodologi Penelitian

Kualitatif. Bandung: PT Remaja Rosdakarya.

Rizaldi. (1994). Musik Gamad di Kotamadya

(Sebuah Bentuk Akulturasi Antara
Budaya Pribumi dan Budaya Barat). Yogyakarta: Pasca Sarjana Universitas Gadjah Mada Yogyakarta. 